Psychology in Western-Europe and a Report on Studies of Pilot Proficiency Measurement. Publication No. 1 of the Western-European Association for Aviation Psychology. Pp. 64. Amsterdam: Swets and Zeutlinger, 1958. 15s.) contains a series of reports on the present position of their work from representatives of most of the countries concerned; the absence of British civilian air-line representatives is conspicuous. It is interesting to learn that most Air Forces or companies are achieving better selection of pilots by scientific testing (despite considerable variations in the relative emphasis placed on paperand-pencil tests, apparatus tests and clinical assess. ments). But it is disappointing to find so little attention, outside the British Institute of Aviation Medicine, to 'human engineering' and training problems such as the effects of stress and fatigue on air-crew, and the design of aircraft equipment and simulators (synthetic training devices). Much the most stimulating paper is one contributed by the American psychologist, Dr. C. W. Bray, on the detailed rocording of pilot performance.

\section{Statistical Review of England and Wales for 1956}

THE Registrar General has recently issued the Commentary Volume on the Statistical Review of England and Wales for 1956 (pp. xvi + 294. London : H.M. Stationery Office, 1958. 16s. 6d. net). As has become established practice, this volume includes some special analyses, as well as commentary on the vital events of the year to which it relates. There is included a nuptiality table for 1951-55, which has been computed in connexion with the fertility analysis of the 1951 census. Such a table is similar to a lifetable, but shows the survivors at various ages up to fifty by marital status. The very high rates of marriage prevailing in 1951-55 are indicated by the fact that of 100,000 females, 90,656 survive to age fifty, of whom only 4,837 have never been married. Of the group of males surviving at age fifteen, only half are still single at twenty-five ; in the case of females the corresponding age is twenty-two. Another special feature included is a comparison of causes of death as ascertained after autopsy with those given on death certificates. The comparison applies to deaths occurring in a number of selected hospitals, and deaths certified by general practitioners are not included. It is shown that in 19 per cent of all cases, new facts were ascertained by the pathologist which had not been reported by the clinician. It was also apparent that deaths from cancer of the lung were under-recorded, in spite of the greater diagnostic facilities that were available.

\section{Insect Toxicologists' Information Service}

Ax a meeting held during the tenth International Congress of Entomology at Montreal, insect toxicologists agreed to co-operate with $\mathrm{Dr}$. D. Dresden of the University of Utrecht in establishing an Insect Toxicologists' Information Service. 'The first Bulletin of the information service was issued recently (Insect Toxicologists' Information Service, Bulletin No. 1. Pp. 106. Vondellaan 6, Utrecht, 1958) by Dr. Dresden. The object of the Service is to enable insect toxicologists all over the world to keep in touch with one another and to be kept up to date with each other's research activities. The Bulletin, which is to be issued annually, is designed for this purpose. The names of the workers on insect toxicology are given, with the laboratory in which they work and some indication of their interests. Some account is also given of the biological material that they work with, since interchange of material may facilitate research. The main body of the Bulletin consists of short notes from the workers themselves on the work they are doing, and it is necessary to submit these notes in order to receive a copy of the Bulletin. Providing the insect toxicologists fulfil their promise to co-operate with Dr. Dresden by submitting their notes regularly, this service should greatly benefit research in this field.

\section{The Nessim Habif Prize}

THE University of Geneva will award in 1959 the Nessim Habif Prize of 10,000 Swiss francs to an author of a work or to an inventor who has made an important contribution to the knowledge or uses of plant cellulose or its synthetic derivatives. Manuscripts must be submitted by May 1 to the Doyen de la Faculté des Sciences de l'Université de Genève, Université, rue de Candolle, Genève, from whom further information can be obtained.

Harkness Fellowships of the Commonwealth Fund

Tre British Committee of Award of the Commonwealth Fund has announced the following elections, among others, to Harkness Fellowships for 1959, tenable for one or two years in the United States: R. H. Cassen (London School of Economics), economics; C. B. Cox (King's College, London), palæontology; R. N. Curnow (Aberdeen), biostatistics ; V. J. Emery (Clare College, Cambridge), nuclear physics ; C. W. J. Granger (Nottingham), economics ; J. F. Hodgess Roper (Magdalen College, Oxford), international economics; S. C. Hunter (Armament Research and Development Establishment), theoretical mechanics; J. L. Jinks (Birmingham), genetics; A. D. McLachlan ('Trinity College, Cambridge), theoretical chemistry; G. P. McNicol (Glasgow), medicine; W. T. Norris (Pembroke College, Cambridge), engineering ; M. L. V. Pitteway (Queens' College, Cambridge), radio physics; D. C. Smith (Queen's College, Oxford), botany; J. B. Taylor (Atomic Weapons Research Establishment), theoretical physies.

\section{International Oceanographic Congress}

The American Association for the Advancement of Science is to hold an International Oceanographic Congress at the United Nations Building in Now York, during August 31-September 12. The Congress is being planned in co-operation with the International Advisory Committee on Marine Sciences of Unesco and the Special Committee on Oceanic Research of the International Council of Scientific Unions. The Congress has the endorsement of the International Association of Physical Oceanography of the International Union of Geodesy and Geophysics. The programme has been designed to afford discussion among scientists interested in diverse fields of specialization within oceanography. Governments as well as universities and scientific organizations abroad are sending delegates to the Congress. It is also suggested that research vessels be sent to New York for the duration of the Congress, to mako it possible to exhibit instruments used at sea and to display the most recent data and collections of biological and geological samples and chemical techniques. Further information can be obtained from the American Association for the Advancement of Science, 1515 Massachusetts Avenue, N.W., Washington 5, D.C. 